\title{
Introductory Analysis of Human Upper Body after Stroke
}

\author{
Esteban Peña-Pitarch, Jordi Vives Costa, Josep A. Lopez Martinez, Anas Al Omar, Iñaki Alcelay \\ Larrión \\ Escola Politècnica Superior d'Enginyeria de Manresa, Spain \\ Neus Ticó-Falguera \\ Xarxa Assistencial Althaia, Spain
}

\begin{abstract}
The most reliable prognostic factors associated with Upper Extremity (UE) recovery are localized motor impairments, especially in the musculature of the hand and abduction of the shoulder in the first days after a stroke. Evaluation of the biomechanics of the hand allows an accurate identification of the motion arcs of the digital joints.

Objective: Assess the prognostic value of the range of motion of the finger joints using an instrumental glove (CyberGlove $\left.I I{ }^{\circledR}\right)$ one week after stroke for UE functional recovery at 6 months.

Methodology: A prospective, longitudinal, observational study with follow-ups at 3-4 days, 1 week, 3 and 6months of patients with UE motor impairment. Variables collected included: demographic data, level of stroke severity (NIHSS), deep sensitivity, sphincter incontinence, Fugl Meyer Assessment of UE (FM-UE), muscle balance with the Medical Research Council (MRC), muscle tone (Modified Ashworth Scale) and pre- and post-stroke functional ability (Barthel Index and Modified Rankin Scale). Active range of motion of the metacarpophalangeal and interphalangeal joints of the index, middle finger, annulary, and little finger was assessed with CyberGlove II ${ }^{\circledR}$ without and against gravity. The dependent variable UE function was evaluated with the Action Research Arm Test (ARAT) categorized as good function (ARAT $\geq 10)$ and poor function $(A R A T<10)$.

Results: 31 patients were included, 18 of which completed the 6-month follow-up. Mean age was 68.2 years $(S D=9.1)$ and $72.2 \%$ were men. A total of $77.8 \%$ of strokes were ischemic, and $50 \%$ of these were lacunar. Mean NIHSS score was $9.2(S D=5.5)$. Motor NIHSS of UE, FM-UE and MRC of the flexion-extension musculature of the digits and wrist were prognostic factors for the recovery of UE function.
\end{abstract}

Keywords: Stroke, Hand simulation, Upper extremity, ARAT test, ADL, Rehabilitation, DOF

\section{INTRODUCTION}

Stroke is one of the leading causes of death in industrialized countries as well as of disability and economic cost in adults. Stroke is associated with a connotation of poor prognosis and difficult recovery. It has an impact at personal, family, social and work level, in addition to producing a high expenditure for all health and social services.

Therapeutic advances of the last years, both in prevention and in diagnostic and therapeutic complexity, have determined a change in stroke management towards the multidisciplinary approach and the creation of specific units that has led to a significant decrease in mortality and its sequels.

Most studies on the evolution and functional prognosis of patients with acute stroke are focused on the assessment of gait recovery and the performance of daily life activities. Predictors of survival, hospital discharge, hospital stay, and overall motor recovery have also been described. Studies on the prediction of 
recovery of specific neurological deficits, such as upper extremity (UE) function, have been increasing in recent years. In this sense, in the last years there are more studies on the specific evaluation of the functional recovery of the UE after having suffered a stroke. This increase in the prevalence of this type of clinical research could also be due to the recent development of validated predictive measures of motor function of UE useful also to establish appropriate therapeutic programs (Chen and Winstein 2009). Approximately $70-80 \%$ of patients with stroke have deficits in UE in the acute phase and $40 \%$ in the chronic phase (Nakayama et al. 1994, Broeks et al. 1999). These deficits limit voluntary movement, coordination, sensitivity, level of physical activity, as well as the realization of activities of daily living (Feys et al. 1998). This aspect implies a limitation and difficulty in their reintegration in their socio-labor environment (Nakayama et al. 1994) and it affects their quality of life (Nichols-Larsen et al. 2005).

Carrying out studies on prognostic factors of the functionality of UE paresis in people who have suffered a stroke is important because of its incidence, its prevalence, its sequels and disability, and its difficulty to predict recovery and functional prognosis of UE.

In another line, several authors are working in design and built an exoskeleton to help rehabilitate UE after stroke. In this sense, (Durairajak et al. 2018), work in a low-cost hand exoskeleton that is design and developed for rehabilitation while the safety rules and regulation kept in mind. Xiao et al. 2018, proposes seven degrees of freedom cable-driven upper limb exoskeleton (CABXLexo-7), which is compact, lightweight, and comfortable for post-stroke patients. For wrist rehabilitation (Saadatgi et al. 2018) presented an experimental implementation and comparative accuracy evaluation of five methods for estimation of human-robot interaction torques are. There are representative works in rehabilitation after stroke, however, we propose a study that obtains data that can help to build and design these exoskeletons.

Therefore, the involvement of UE and specifically the hand in diseases such as stroke implies in these patients a significant alteration in the performance of many activities of daily living, as well as motor, sensory and body expression limitations that can seriously affect the relationship of these people with their environment.

The aim of the present study is the simulation in patients at the beginning and at the end of six months of suffering from a stroke. The intention of this work is to show a novel virtual environment to simulate the improvement of the functions of the upper extremity a few days after having suffered a stroke and to simulate its recovery under a rehabilitation program.

This document continues with a section of materials and methods. Next section is dedicated to the results, the next section is the discussion and it ends with the conclusions.

\section{MATERIALS AND METHODS}

Patients admitted due to acute stroke and motor involvement of UE in the neurology department of Sant Joan de Deu Hospital who met the inclusion criteria and none of the exclusion criteria were selected. The inclusion criteria were:

- Patients older than 18 years.

- Patients who have suffered a stroke for the first time with motor deficit in the UE, admitted to the service of Sant Joan de Deu hospital, with confirmation of neuroimaging brain injury during the first 48 hours.

- Patients without cognitive impairment that makes it difficult for them to understand and follow up the assessments.

- Patients who before the stroke were independent in their activities of daily living (ADL).

- To accept to participate in the study and signing the informed consent.

The exclusion criteria were:

- Patients with deficits and sequelae in their UE of any pre-stroke etiology.

- Patients with subsequent follow-up and control difficulties.

- Patients with terminal illness with a life expectancy of less than six months. 
Withdrawal criteria were also taken into account, such as:

- Appearance of a new stroke during follow-up.

- Onset of concomitant pathology affecting the patient's vital prognosis and/or subsequent followup.

- That the patient decides voluntarily.

- Lack of compliance and collaboration on the part of the patient.

- Death of the patient.

In total, 18 patients who met the inclusion criteria were selected. The first follow-up visit was performed 3-4 days after the stroke and data were collected during hospital admission. The next visit and data collection was performed at 7 days, at 3 months and the last one was at 6 months' post-stroke. In this last visit, one of the patients was able to perform the whole validated Action Research Arm Test (ARAT) table. It is in this last visit that we will focus the simulation and in which we will create the virtual simulation environment.

\section{Evaluation of the functionality of the US with the ARAT test. With CyberGlove IIß glove and without}

This evaluation with ARAT was only carried out at the last follow-up visit (visit 4). The equipment to do this test was achieved thanks to an agreement with the School of Engineering of Manresa, who prepared it according to the instructions and measures obtained of the model described by Lyle (Lyle 1981), as can be seen in Figure 1.

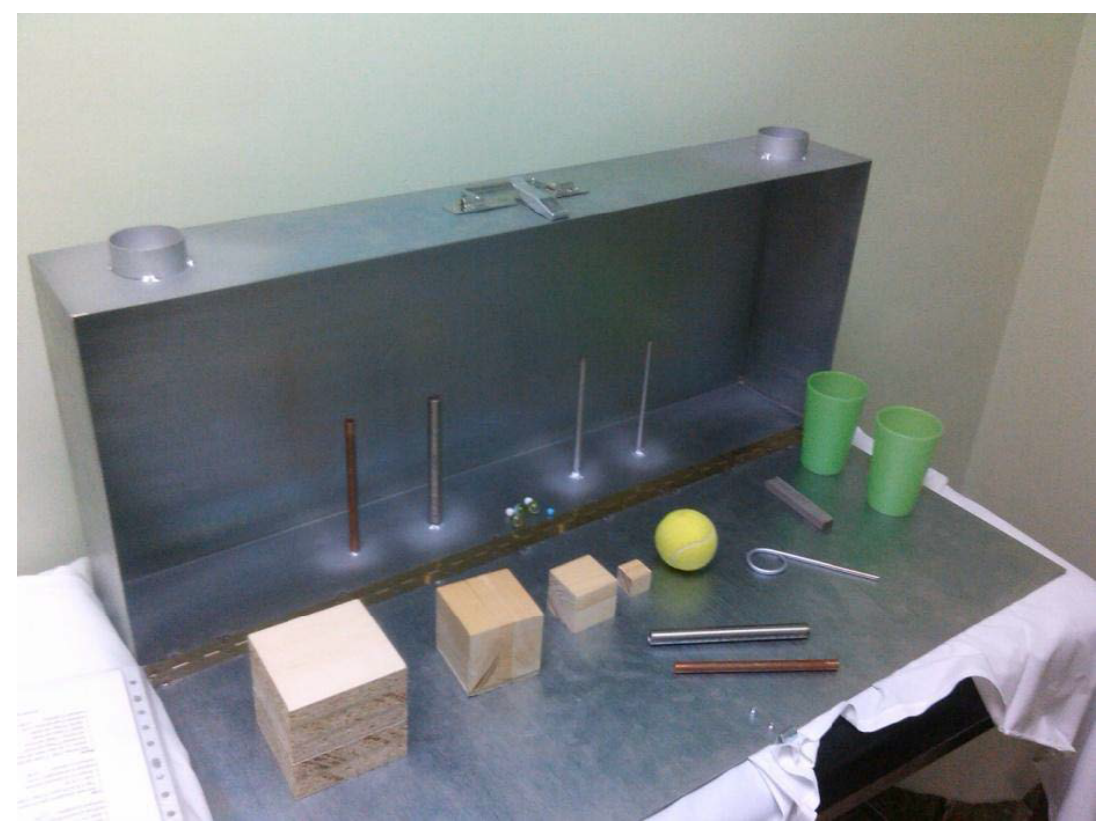

Figure 1: ARAT test

On visit 4, after evaluating the patient clinically and neurologically with the evaluations and scales described previously, the ARAT was first passed without the glove and then with it Glove, as shown in figure 2. 


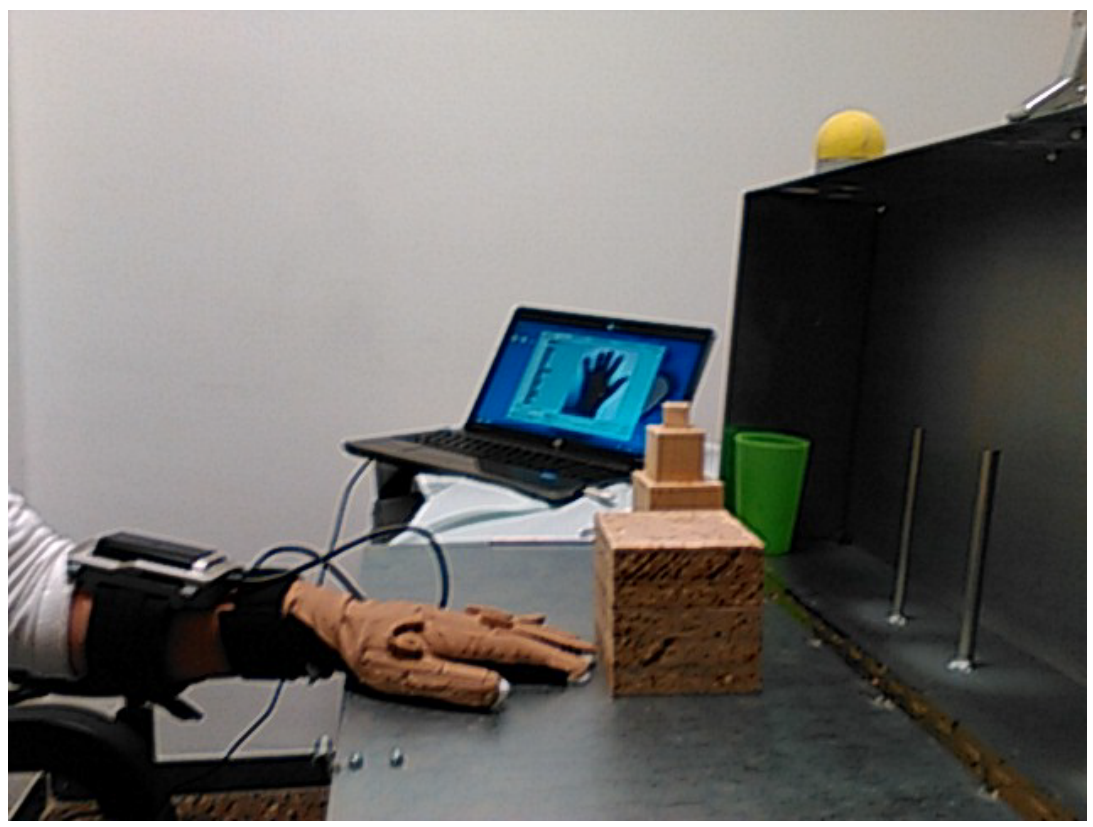

Figure 2: Patient doing the ARAT test

\section{Assessment of joint balance with Cyber-Globe II® glove}

In order to obtain information on the angles of the joints of the hand, the 18 -sensor Cyber-Globe II® glove was used, which also has a resolution of one degree, with a ratio of 90 measurements/s. An interface for capturing data with the glove was made, as shown in Figure 3. After obtaining all the data with the glove, the data were converted to the hand model proposed by the authors (Peña-Pitarch et al. 2014). The hand model is 25 degrees of freedom (DOF), not counting flexion/extension (F/E) and adduction/abduction $(\mathrm{Ad} / \mathrm{Ab})$ of the wrist, as shown in figure 4.

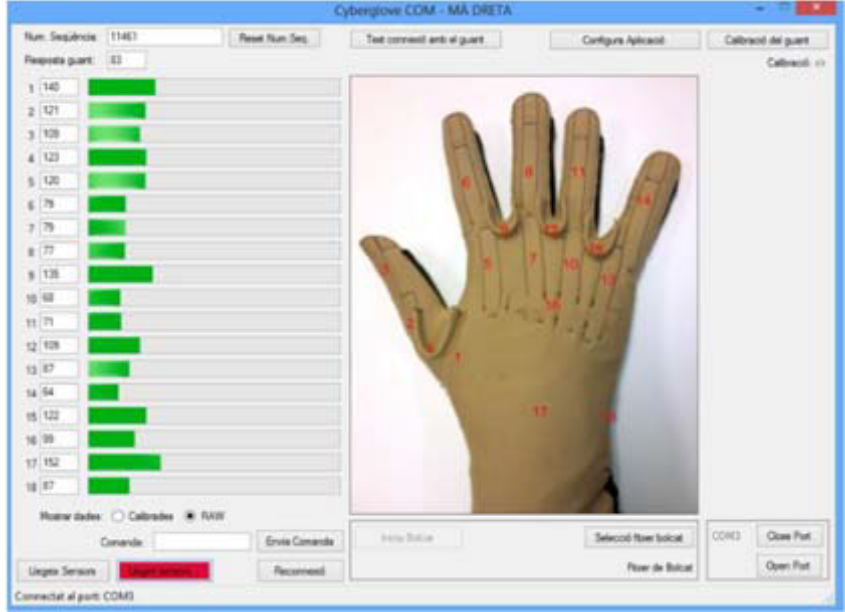

Figure 3: Screenshot of the data collection and numbering of the sensors. 


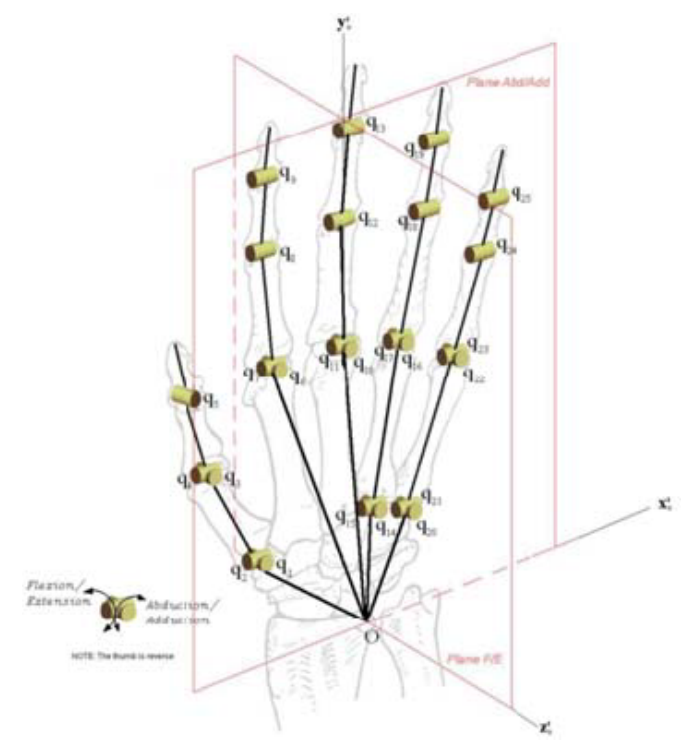

Figure 4: Hand with 25 DOF. Rear view right hand.

The procedure to pass the readings of the 18 sensors of the glove to the 25 DOF model is the same for each joint with its movement $(\mathrm{q})$. This procedure is based on a linear interpolation, since there are DOF that depend on the readings of one or more sensors, and takes into account the maximum and minimum reading of the movement of each sensor and the maximum and minimum of the range of movement (flexion and extension) of each hand joint (q). Table 1 shows the movements of the joints that each sensor picks depending on where it is located. Sensors numbers are shown in figure 3 . Table 2 shows the range of motion for each joint.

The minimum value corresponds to the position of the joint when you perform an extension or abduction, and the value maximum, when the joint flexes or enlarges. Table 3 shows the minimum values and maximum that collects the sensors of the CyberGlove II ${ }^{\circledR}$ glove.

Table 1. Movements of the joints that each sensor picks depending on where it is located

\begin{tabular}{|c|c|c|c|}
\hline Sensor & Movement & Joint & Finger \\
\hline 1 & $\mathrm{~F} / \mathrm{E}$ & Metacarpal trapezius & Thumb \\
\hline 2 & $\mathrm{~F} / \mathrm{E}$ & Metacarpophalangeal (MCP) & Thumb \\
\hline 3 & $\mathrm{~F} / \mathrm{E}$ & Interphalangeal (IP) & Thumb \\
\hline 4 & $\mathrm{Ab} / \mathrm{Ad}$ & Metacarpal trapezius & Thumb \\
\hline 5 & $\mathrm{~F} / \mathrm{E}$ & Metacarpophalangeal & Index \\
\hline 6 & $\mathrm{~F} / \mathrm{E}$ & Proximal Interphalangeal (PIP) & Index \\
\hline 7 & $\mathrm{~F} / \mathrm{E}$ & Metacarpophalangeal & Middle \\
\hline 8 & $\mathrm{~F} / \mathrm{E}$ & Proximal Interphalangeal & Middle \\
\hline 9 & $\mathrm{Ab} / \mathrm{Ad}$ & Between two fingers & Index/middle \\
\hline 10 & $\mathrm{~F} / \mathrm{E}$ & Metacarpophalangeal & Ring \\
\hline 11 & $\mathrm{~F} / \mathrm{E}$ & Proximal Interphalangeal & Ring \\
\hline 12 & $\mathrm{Ab} / \mathrm{Ad}$ & Between two fingers & Index/middle \\
\hline 13 & $\mathrm{~F} / \mathrm{E}$ & Metacarpophalangeal & Small \\
\hline 14 & $\mathrm{~F} / \mathrm{E}$ & Proximal Interphalangeal & Small \\
\hline 15 & $\mathrm{Ab} / \mathrm{Ad}$ & Between two fingers & Ring/small \\
\hline 16 & $\mathrm{Arch}$ & Metacarpal & Middle/ring/small \\
\hline
\end{tabular}




\begin{tabular}{|c|c|l|l|}
\hline 17 & F/E & Carp cubital radius & Wrist \\
\hline 18 & $\mathrm{Ab} / \mathrm{Ad}$ & Carp cubital radius & Wrist \\
\hline
\end{tabular}

Where $\mathrm{F} / \mathrm{E}$ is Flexion/Extension and $\mathrm{Ab} / \mathrm{Ad}$ is Abduction/Adduction movements.

Table 2. Range of movements for the joints of the fingers; H is hyperextension (in degrees)

\begin{tabular}{|l|c|c|c|c|}
\hline Joint \Finger & \multicolumn{1}{|l|}{ Index } & Middle & \multicolumn{1}{l|}{ Ring } & \multicolumn{1}{l|}{ Small } \\
\hline $\mathrm{MCP}(\mathrm{E} / \mathrm{F})$ & $0 / 80$ & $0 / 80$ & $0 / 80$ & $0 / 80$ \\
\hline $\mathrm{MCP}(\mathrm{Ab} / \mathrm{Ad})$ & $13 / 42$ & $8 / 35$ & $14 / 20$ & $19 / 33$ \\
\hline $\mathrm{PIP}(\mathrm{F} / \mathrm{E})$ & $0 / 100$ & $0 / 100$ & $0 / 100$ & $0 / 100$ \\
\hline $\mathrm{DIP}(\mathrm{F} / \mathrm{E})$ & $10 \mathrm{H} / 90$ & $10 \mathrm{H} / 100$ & $20 \mathrm{H} / 100$ & $30 \mathrm{H} / 100$ \\
\hline
\end{tabular}

Where DIP is distal interphalangeal.

Table 3. Minimum and maximum values given by each CyberGlove II ${ }^{\circledR}$ glove sensor

\begin{tabular}{|c|c|c|}
\hline Sensor & Minimum & Maximum \\
\hline 1 & 55 & 180 \\
\hline 2 & 105 & 160 \\
\hline 3 & 40 & 215 \\
\hline 4 & 120 & 131 \\
\hline 5 & 105 & 135 \\
\hline 6 & 56 & 206 \\
\hline 7 & 20 & 130 \\
\hline 8 & 50 & 186 \\
\hline 9 & 15 & 155 \\
\hline 10 & 10 & 162 \\
\hline 11 & 36 & 202 \\
\hline 12 & 1 & 146 \\
\hline 13 & 15 & 208 \\
\hline 14 & 43 & 216 \\
\hline 15 & 50 & 168 \\
\hline 16 & 40 & 245 \\
\hline 17 & 85 & 160 \\
\hline 18 & 36 & 202 \\
\hline
\end{tabular}

The implementation of a virtual model of 25 DOF allows a very realistic simulation of the hand. The procedure for passing the readings from the 18 glove sensors to the 25 DOF model (hand only) will be the same for each joint. This procedure is based on linear interpolation, since there are some DOFs that depend on the readings of one or more sensors and takes into account the maximum and minimum reading of the movement of each sensor and the maximum and minimum of the range of motion of each joint of the hand.

Once the assessment of the joint balance of each union and its subsequent conversion to the hand model with the 25 DOF was made, its implementation in the virtual environment of Blender -free code programwas carried out.

\section{Simulation}


Our approach for each of the patients has been using the model shown in figure 5. In this model in addition to the $25 \mathrm{DOF}$ of the hand were added 4 more DOF, two for the wrist, in order to simulate the $\mathrm{F} / \mathrm{E}$ of the same and the other for $\mathrm{Ab} / \mathrm{Ad}$. About the other two DOFs remaining, one is for the $\mathrm{F} / \mathrm{E}$ of the elbow and the other is for supination/ pronation of the arm. In this work we have only focused on the study of the arm, not counting the shoulder, since we have considered more DOF focused on object grabbing. The future simulation of the trunk up to the hand is not ruled out.

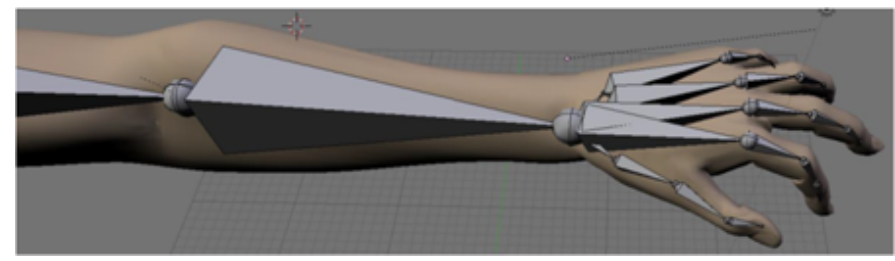

Figure 5: Left arm implemented in Blender with 29 DOF

The mathematical formulation applied to the model was previously published in (Peña-Pitarch et al. 2014) and it is as follows. The position vector is defined by $\mathbf{p}\left(\mathbf{q}^{i}\right)$ which with respect to the local coordinate system will be:

$$
\left[\begin{array}{c}
\mathbf{p}\left(\mathbf{q}^{i}\right) \\
1
\end{array}\right]={ }^{0} A_{1}{ }^{1} A_{2} \ldots{ }^{n-1} A_{n}\left[\begin{array}{l}
0 \\
0 \\
0 \\
1
\end{array}\right]
$$

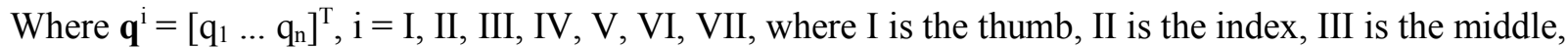
IV the annular and V the pinkie, VI is for the wrist and VII for the arm. Where $\mathrm{n}$ is the total number of DOF, in this case it is 29.

To move it to a global coordinate system located on the shoulder, the position vector is now:

$$
\left[\begin{array}{c}
\mathbf{w}\left(\mathbf{q}^{i}\right) \\
1
\end{array}\right]=\left[{ }^{0} \mathbf{H}_{i}\right]\left[\begin{array}{c}
\mathbf{p}\left(\mathbf{q}^{i}\right) \\
1
\end{array}\right]
$$

Figure 6 shows a screenshot of Blender, where on the left side we can see the code implemented with Python and allows to simulate each patient once the data obtained by the glove has been converted to the described model of 29 DOF, where the two of the elbows have been approximated by means of a goniometer.

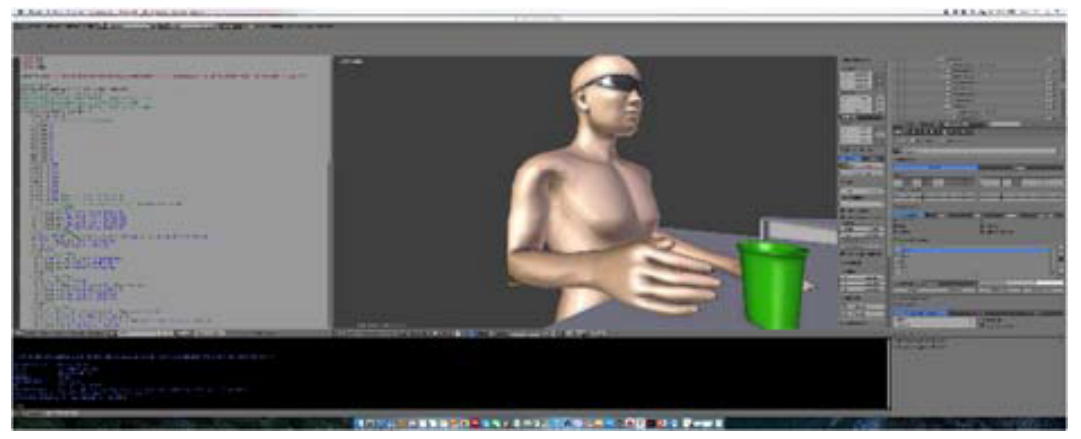

Figure 6: Screenshot of a moment of the simulation of a patient.

\section{RESULTS}


The prognostic capacity of each of the joints in the functional recovery at 6 months according to the ARAT was evaluated both for the motion without gravity and for the movement against gravity when performing F/E of the fingers as well as the gain of movement experienced by each of these joints at 6 months' post-stroke. The joints corresponding to the metacarpo-phalangic and interphalangeal joints of all the fingers were evaluated.

\section{Joints q7, q8, q9. Index finger (F/E).}

The mean $\mathrm{q}_{7}$ joint and during the six-month follow-up the ARAT group $\geq 10$ experienced a gain of 65 degrees in the F/E movement range without severity. At three months the gain of movement was 26 degrees higher in the ARAT group $\geq 10$ than in the ARAT group $<10$. However, at six months the ARAT $\geq 10$ group experienced a gain of 41 degrees in the same movement but against gravity. As for the joint q8 the gain was 21 degrees without gravity and between 19 to 39 degrees in the movement against gravity, for the group ARAT $\geq 10$. The joint $q 9$, the same group obtained a gain of 14 degrees and against gravity a gain of between 13 and 26 degrees.

\section{Joints $q_{11}, q_{12}, q_{13}$. Middle Finger (F/E).}

Always referring to the same group (ARAT $\geq 10$ ), in the joint $\mathrm{q}_{11}$ a gain of 22 degrees was obtained in the motion without gravity and between 14 and 17 . The joint q12 without gravity experienced 21 degrees of gain and between 19 and 30 degrees in motion against gravity. Similarly, $\mathrm{q}_{13}$ gained 14 degrees and between 13 and 20 degrees with the same movement.

\section{Joints $q_{17}, q_{18}, q_{19}$. Finger ring (F/E).}

Similarly, the $\mathrm{q}_{17}$ joint experienced a gain of 18 degrees without gravity and between 15 and 24 degrees against gravity. The joints $\mathrm{q}_{18}$ and $\mathrm{q}_{19}$, had gains of 22 and 15 degrees respectively and between 15 and 31 degrees.

Joints $q_{23}, q_{24}, q_{25}$. Pinky finger (F/E).

Likewise, the joint $\mathrm{q}_{23}$ experienced a gain of 19 degrees without gravity and between 12 and 24 degrees against gravity. The joints $\mathrm{q}_{24}$ and $\mathrm{q}_{25}$, had gains of 28 and 18 degrees respectively and between 13 and 35 degrees.

ARAT bivariate analysis table 6 months. Clinical and functional characteristics at 3-4 days associated with ARAT.

Table 4. ARAT bivariate analysis 6 months

\begin{tabular}{|c|c|c|c|}
\hline Assessment 3-4 days & ARAT $<\mathbf{1 0}$ N=6 & ARAT $\geq \mathbf{1 0 ~ N = 1 2}$ & p-value \\
\hline $\begin{array}{c}\text { Deep sensitivity } \\
\text { No altered } \\
\text { Altered }\end{array}$ & $\begin{array}{c}2(14,3 \%) \\
4(100,0 \%)\end{array}$ & $\begin{array}{c}12(85,7 \%) \\
0(0,0 \%)\end{array}$ & $0,005^{\mathrm{b}}$ \\
\hline $\begin{array}{c}\text { Urinary incontinence } \\
\text { No }\end{array}$ & $3(20,0 \%)$ & $12(80,0 \%)$ & $0,025^{\mathrm{b}}$ \\
\hline
\end{tabular}




\begin{tabular}{|c|c|c|c|}
\hline Yes & $3(100 \%)$ & $0(0,0 \%)$ & \multirow[b]{2}{*}{$0,245^{\mathrm{b}}$} \\
\hline $\begin{array}{c}\text { Fecal incontinence } \\
\text { No } \\
\text { Yes }\end{array}$ & $\begin{array}{l}4(26,7 \%) \\
2(66,7 \%)\end{array}$ & $\begin{array}{c}11(73,3 \%) \\
1(33.3 \%)\end{array}$ & \\
\hline $\begin{array}{c}\text { Hemineglect } \\
\text { No } \\
\text { Yes } \\
\end{array}$ & $\begin{array}{l}2(14,3 \%) \\
4(100 \%) \\
\end{array}$ & $\begin{array}{c}12(85,7 \%) \\
0(0,0 \%)\end{array}$ & 0,005 \\
\hline $\begin{array}{l}\text { Muscular tone } \\
\text { Normal } \\
\text { Flaccidity }\end{array}$ & $\begin{array}{c}0(0,0 \%) \\
6(54,5 \%)\end{array}$ & $\begin{array}{l}7(100 \%) \\
5(45,5 \%)\end{array}$ & $0,038^{b}$ \\
\hline \multicolumn{4}{|l|}{ NIHSS } \\
\hline NIHSS & $14,8(\mathrm{DE}=4,8)$ & $6,4(\mathrm{DE}=3,3)$ & $0,005^{\mathrm{a}}$ \\
\hline $\begin{array}{c}\text { NIHSS sensitivity } \\
\text { Normal } \\
\text { Hypoaesthesia }\end{array}$ & $\begin{array}{l}1(20,0 \%) \\
5(38,5 \%)\end{array}$ & $\begin{array}{l}4(80,0 \%) \\
6(61,5 \%)\end{array}$ & $0,615^{\mathrm{b}}$ \\
\hline $\begin{array}{c}\text { NIHSS motor UE } \\
\text { Normal } \\
\text { Claudicate } \\
\text { Notovercome gravity } \\
\text { Motionless } \\
\end{array}$ & $\begin{array}{c}0(0,0 \%) \\
0(0,0 \%) \\
1(20,0 \%) \\
5(83,3 \%)\end{array}$ & $\begin{array}{l}3(100,0 \%) \\
4(100 \%) \\
4(80,0 \%) \\
1(66,7 \%) \\
\end{array}$ & 0,013 \\
\hline $\begin{array}{l}\text { NIHSS orientation } \\
\text { Responds two orders } \\
\text { Responds one order } \\
\text { Not perform any } \\
\end{array}$ & $\begin{array}{l}3(23,1 \%) \\
1(33,3 \%) \\
2(100 \%) \\
\end{array}$ & $\begin{array}{c}10(76,9 \%) \\
2(66,7 \%) \\
0(0,0 \%) \\
\end{array}$ & 0,123 \\
\hline $\begin{array}{c}\text { NIHSS orders } \\
\text { Performs two tasks } \\
\text { Performs one task }\end{array}$ & $\begin{array}{l}3(20,0 \%) \\
3(100 \%)\end{array}$ & $\begin{array}{l}12(80 \%) \\
0(0,0 \%)\end{array}$ & $0,025^{\mathrm{b}}$ \\
\hline $\begin{array}{c}\text { NIHSS conjugated gaze } \\
\text { Normal movement } \\
\text { Parcial paralysis }\end{array}$ & $\begin{array}{l}3(20,0 \%) \\
3(100 \%)\end{array}$ & $\begin{array}{c}12(80,0 \%) \\
0(0,0 \%)\end{array}$ & $0,025^{\mathrm{b}}$ \\
\hline $\begin{array}{c}\text { NIHSS Visual fields } \\
\text { No defects } \\
\text { Parcial hemianopsia } \\
\text { Full hemianopsia } \\
\end{array}$ & $\begin{array}{l}2(16,7 \%) \\
1(50,0 \%) \\
3(75,0 \%) \\
\end{array}$ & $\begin{array}{c}10(83,3 \%) \\
1(50,0 \%) \\
1(25,0) \\
\end{array}$ & 0,082 \\
\hline $\begin{array}{c}\text { NIHSS Extension-inatencion } \\
\text { Withoutmodifications } \\
\text { Alteration a modality } \\
\text { Severe hematution } \\
\end{array}$ & $\begin{array}{l}2(15,4 \%) \\
4(100 \%) \\
0(0,0 \%)\end{array}$ & $\begin{array}{l}11(84,6 \%) \\
0(0,0 \%) \\
1(100 \%)\end{array}$ & 0,004 \\
\hline No mechanical pain & $6(33,3 \%)$ & $12(66,7 \%)$ & - \\
\hline No neuropathic pain & $6(33,3 \%)$ & $12(66,7 \%)$ & - \\
\hline $\begin{array}{c}\text { Finger extensors } \\
0-2 \\
3-5 \\
\end{array}$ & $\begin{array}{c}6(42,9 \%) \\
0(0,0 \%)\end{array}$ & $\begin{array}{l}8(57,1 \%) \\
4(100 \%) \\
\end{array}$ & $0,245^{\mathrm{b}}$ \\
\hline $\begin{array}{c}\text { Flexors fingers } \\
0-2 \\
3-5 \\
\end{array}$ & $\begin{array}{c}6(50,0 \%) \\
0(0,0 \%)\end{array}$ & $\begin{array}{l}6(50,0 \%) \\
6(100 \%) \\
\end{array}$ & $0,054^{\mathrm{b}}$ \\
\hline $\begin{array}{c}\text { Wrist extensions } \\
0-2 \\
3-5 \\
\end{array}$ & $\begin{array}{c}6(42,9 \%) \\
0(0,0 \%)\end{array}$ & $\begin{array}{l}8(57,1 \%) \\
4(100 \%)\end{array}$ & $0,245^{b}$ \\
\hline $\begin{array}{c}\text { Flexors wrist } \\
0-2 \\
3-5\end{array}$ & $\begin{array}{c}6(50,0 \%) \\
0(0,0 \%)\end{array}$ & $\begin{array}{l}6(50,0 \%) \\
6(100 \%)\end{array}$ & $0,054^{\mathrm{b}}$ \\
\hline $\begin{array}{c}\text { Elbow extensors } \\
0-2\end{array}$ & $6(50,0 \%)$ & $6(50,0 \%)$ & $0,054^{\mathrm{b}}$ \\
\hline
\end{tabular}




\begin{tabular}{|c|c|c|c|}
\hline $3-5$ & $0(0,0 \%)$ & $6(100 \%)$ & \\
\hline $\begin{array}{c}\text { Flexors elbow } \\
0-2\end{array}$ & $\begin{array}{c}(54,5 \%) \\
0(0,0 \%)\end{array}$ & $\begin{array}{c}5(45,5 \%) \\
7(100 \%)\end{array}$ & $0,038^{\mathrm{b}}$ \\
\hline $3-5$ & $\begin{array}{c}(54,5 \%) \\
0(0,0 \%)\end{array}$ & $\begin{array}{c}5(45,5 \%) \\
7(100 \%)\end{array}$ & $0,038^{\mathrm{b}}$ \\
\hline $\begin{array}{c}\text { Abduction shoulder } \\
3-2\end{array}$ & $\begin{array}{c}(50,0 \%) \\
0(0,0 \%)\end{array}$ & $\begin{array}{c}6(50,0 \%) \\
6(100 \%)\end{array}$ & $0,054^{\mathrm{b}}$ \\
\hline $\begin{array}{c}\text { Flexors shoulder } \\
0-2\end{array}$ & $4,8(\mathrm{DE}=2,0)$ & $31,8(\mathrm{DE}=22,3)$ & $0,003^{\mathrm{a}}$ \\
\hline $3-5$ & $7,5(\mathrm{DE}=3,5)$ & $27,5(\mathrm{DE}=10,6)$ & $0,001^{\mathrm{b}}$ \\
\hline Fugl Meyer UE & $0(0,0 \%)$ & $2(100 \%)$ & $0,529^{\mathrm{b}}$ \\
\hline Barthel index & $6(37,5 \%)$ & $10(62,5 \%)$ & \\
\hline Rankin scale & $0-2$ &
\end{tabular}

${ }^{\mathrm{a} U}$ Mann-Whitney; Fisher exact prove; ${ }^{\mathrm{c} p}$-value bilateral Monte Carlo.

\section{DISCUSSION}

The measurement of the flexion and extension movement of the finger joints is a part of the basic exploration of many clinicians in their daily explorations. This measurement can be done quickly, simply and next to the patient's bed. The instrumentation of the measurement of the amplitude of the active range of motion has allowed us to obtain a more accurate data of the active movement of each joint and to implement it in the virtual environment as well as to simulate this movement for each patient. When analyzing the range of motion (difference between minimum and maximum F/E) of each joint, significant differences were observed at 3 months between the two ARAT groups in the interphalangeal joints of the four fingers, and in the metacarpal joints -phalangeal of the ring finger and pinky in both positions, without and against gravity. Nevertheless, these data do not provide much information because at 3 months is considered that many patients have recovered most of the functionality, and it is not an early assessment that allows us to define individualized programs of rehabilitation treatment. Only in the evaluation of the initial week, there are significant changes in the proximal and distal interphalangeal joints of the index and the annular of the hand in the movement against gravity. Of these two fingers, the interphalangeal joints with more joint gain are those of the ring finger. The gain was 22 degrees with respect to 19 in the proximal interphalangeal joint, and 15 with respect to 13 degrees in the distal interphalangeal joint of the ring finger with respect to the index finger.

Thus, in the analysis of the range of motion between the two ARAT groups, the joints with the greatest capacity predicted at the week are the proximal and distal interphalangeal of the index finger and the annular one in the position against gravity, and of these two the ring finger.

The active range of flexion of each finger of the hand, flexion of the back and elbow, pronation and supination of the elbow, and flexion and extension of the wrist were examined in (Beebe et al. 2009). These authors observed that the active flexion of the middle finger and the presence of abduction in the lower back evaluated in the first 3 weeks post stroke had better predictive capacity at three months of the stroke than the rest of the fingers and joints of UE. In contrast, in another study, it was the active extension of the index and middle fingers against severity at 3 weeks of stroke, which were strongly predictive of recovery at 13 weeks post stroke (Lang et al. 2006). Mirbagheri et al. (2008) identified the active range of motion and maximal voluntary contraction of elbow flexion and extension movements at 4 weeks of stroke as predictors of UE motor recovery.

Table 4 shows the evolution of the clinical and functional characteristics of the patients according to the ARAT and for each one of the evaluations that were performed.

The group of patients with ARAT $\geq 10$ had a mean NIHSS score of $6.4(\mathrm{SD}=3.3)$, whereas the group of patients with an ARAT $<10$ had a mean of $14.8(\mathrm{SD}=4.8)$ in the 3-4 days' assessment. At 3-4 days, in 
the ARAT group $<10$ the patients had a mean FM-UE of $4.8(\mathrm{SD}=2.2)$, and in the ARAT group $\geq 10$, a mean of $31.8(\mathrm{SD}=22.3)$. In the Barthel index, the mean was $7.5(\mathrm{SD}=3.5)$ in the ARAT group $<10$ and $27.5(\mathrm{SD}=10)$ in the ARAT group $>10$.

Each patient in the ARAT group $\geq 10$ presented alteration of the deep sensitivity, but had no urinary incontinence or hemi-neglect. All patients in the ARAT group $<10$ had an ERM $\geq 3$ in all follow-ups that were made (See table 4).

The movement of the fingers of the hand is important to acquire the skill and for the manipulation of objects that determine the proper functionality of the ES. The hand has multiple functions; the most important are touch, which is a sensitive function and grip, which is a motor function. To carry out these functions, the hand adopts different positions according to the type of grip it has to do. In all these positions involve more or less fingers, but in general, the little finger intervenes when it is necessary to grasp objects of greater weight and volume. All fingers are important for manipulation and grasping, but it is possible that the one that does not so much determine the functionality of UE is the little finger because, it is only used when objects are heavy and bulky.

The results of this study highlight the predictive capacity for the recovery of UE function at 6 months after stroke.

\section{CONCLUSION}

The biomechanical evaluation of the fingers and their simulation in a virtual environment may facilitate the stratification of the patients in groups at risk according to the prognosis of the recovery of the paresis UE. This fact would help health professionals to make a more individual planning of neuro-rehabilitating treatment of patients who have suffered a stroke. Adequate patient selection would increase the efficiency of rehabilitation services.

The data obtained with the Cyber-Globe II@ instrumentation glove are useful for designing technical aids or orthoses that help to promote independence in the activities of the daily life of the patients who need it. These data have been adapted to the virtual model with $29 \mathrm{DOF}$, which has allowed the simulation of each patient, giving an approximation of the abilities and limitations in their ADL.

The virtual simulation of the arm and hand in patients with stroke gives a new objective tool to physicians that allows simulating the evolution of deficits in some patients. The relevance of this work for patients affected by these deficits is that in the first visit to the doctor after the stroke it is possible to know through the simulation the evolution of their functional recovery. Another relevance is that the arm and hand model has been implemented with parametric lengths and can be extrapolated to other affected patients with the same deficits. Finally, ergonomists can be given data on hand movements and help design new products for people with reduced mobility due to a partial recovery after having followed the rehabilitation program.

\section{ACKNOWLEDGMENT}

This work was partially supported by the Spanish government (projectsDPI2013-40882-P and DPI201680077-R).

\section{REFERENCES}

Chen S, \& Winstein C. (2009). A systematic review of voluntary arm recovery in hemiparetic stroke: critical predictors for meaningful outcomes using the international classification of functioning, disability, and health. J NeurolPhysTher. 33(1), 2-13 Nakayama H.,Jorgensen, H., Raaschou, H., \& Olsen, T. (1994). Recovery of upper extremity function in stroke patients: the Copenhagen Stroke Study. Arch Phys Med Rehabil. 75(4), 394 398. 
Broeks J., Lankhorst, G., Rumping, K., \& Prevo, A. (1999). The long-term outcome of arm function after stroke: results of a follow-up study. DisabilRehabil. 21(8), 357-364.

Feys, H., De Weerdt, W., Selz, B., Cox Steck, G., Spichiger, R., \& Vereeck, L. (1998). Effect of a therapeutic intervention for the hemiplegic upper limb in the acute phase after stroke: a single blind, randomized, controlled multicenter trial. Stroke. 29(4), 785-792.

Nichols-Larsen, D., Clark, P., Zeringue, A., Greenspan, A., \& Blanton, S. (2005). Factors influencing stroke survivors' quality of life during subacute recovery. Stroke. 36(7),1480-1484. Durairajah, V., Gobee, S., Rauf, W., Ngie, K.S. \& Lim, J.H.A. (2018). Design and Development of Low Cost Hand Exoskeleton for Rehabilitation. 2nd International Conference for Innovation in Biomedical Engineering and Life Sciences, IFMBE Proceedings 67, 107-110.

Xiao, F., Gao, Y., Wang, Y., Zhu, Y. \& Zhao, J. (2018). Design and evaluation of a 7-DOF cable-driven upper limb exoskeleton. Journal of Mechanical Science and Technology. 32 (2), 855-864.

Saadatgi, M., Long, D.C. \& Celik, O. (2018). Comparison of Human-Robot Interaction Torque Estimation Methods in a Wrist Rehabilitation Exoskeleton. Journal of Intelligent \& Robotic Systems. https://doi.org/10.1007/s10846-018-0786-8.

Lyle, R. (1981). A performance test for assessment of upper limb function in physical rehabilitation treatment and research. Int $J$ Rehabil Res. 4(4):483-92.

Peña-Pitarch, E., Tico-Falguera, N., \& Yang, J. (2014). Virtual human hand: model and kinematics. Computer Methods BiomechBiomedEngin. 17(5), 568-579.

Beebe, J., \& Lang, C. (2009). Active Range of Motion Predicts Upper Extremity Function 3 Months After Stroke. Stroke. 40(5), 1772-1779.

Lang, C., Wagner, J., Edwards, D., Sahrmann, S., \& Dromerick, A. (2006). Recovery of grasp versus reach in people with hemiparesis poststroke. Neurorehabil Neural Repair.20(4), 444-454. Mirbagheri, M., \& Rymer, W. (2008). Time-course of changes in arm impairment after stroke: Variables predicting motor recovery over 12 months. ArchPhysMedRehabil. 89(8), 1507-1513. 